\title{
The Correlation Between the Anxiety and the Amount of the Sweat Gland Secretion in the Patients with Palmar Hyperhidrosis
} \author{
Andi Wardihan Sinrang ${ }^{4}$ \\ ${ }^{1}$ Department of Dermatology, Faculty of Medicine, Hasanuddin University, Makassar, Indonesia \\ ${ }^{2}$ Department of Biostatistic, Faculty of Public Health, Hasanuddin University, Makassar, Indonesia \\ ${ }^{3}$ Department of Psychiatry, Faculty of Medicine, Hasanuddin University, Makassar, Indonesia \\ ${ }^{4}$ Department of Physiology, Faculty of Medicine, Hasanuddin University, Makassar, Indonesia
}

Regina Mihardja ${ }^{1}$, Alwi Mappiasse ${ }^{1}$, Anis Irawan Anwar ${ }^{1}$, Arifin Seweng ${ }^{2}$, Sonny Lisal ${ }^{3}$,

Email address:

regina_mihardja@yahoo.co.id (R. Mihardja)

\section{To cite this article:}

Regina Mihardja, Alwi Mappiasse, Anis Irawan Anwar, Arifin Seweng, Sonny Lisal, Andi Wardihan Sinrang. The Correlation Between the Anxiety and the Amount of the Sweat Gland Secretion in the Patients with Palmar Hyperhidrosis. American Journal of Clinical and Experimental Medicine. Vol. 4, No. 5, 2016, pp. 138-145. doi: 10.11648/j.ajcem.20160405.15

Received: July 21, 2016; Accepted: August 31, 2016; Published: September 29, 2016

\begin{abstract}
Hyperhidrosis is also known as polyhidrosis or sudorrhea, which defines as the secretion of the sweat that exceeds the amount necessary for thermoregulation of the body. Palmar hyperhidrosis is excessive sweat secretion and is limited to the area of the palm. Anxiety is associated with feelings of uncertainty and helplessness. This emotional state does not have a specific object. Conditions subjectively experienced and communicated in interpersonal relationships. The purpose of this study was to determine the relationship between anxiety with the number of sweat glands secretion in patients with palmar hyperhidrosis. This study was an observational study with cross sectional design and analytical approach, conducted at Outpatient Clinic of Dermatology and Venereology Department of Dr. Wahidin Sudirohusodo Makassar, Hasanuddin University Hospital, and Senior High School in Makassar. This study began in February to April 2016. The number of samples are 40 people who suffered from palmar hyperhidrosis with the largest age distribution that is less than 20 years as many as 26 samples (65.0\%). A total of 40 samples (100.0\%) do not suffer secondary disorder, experiencing excessive sweating for at least 6 months, lasting at least one week, with bilateral symmetrical distribution, the onset of age 25 or younger and no sweat at night day. Family history of suffering from palmar hyperhidrosis were found in 12 samples $(30.0 \%)$. There is a daily impact on palmar hyperhidrosis patients as many as 13 samples $(32.5 \%)$. Students are the most in this study as many as 26 samples $(65.0 \%)$. The onset of age palmar hyperhidrosis is the most at the age of 13 to 18 years from 21 samples $(52.2)$. The severe palmar hyperhidrosis is the most in this study, there are 16 samples $(40.0 \%)$. The degrees of moderate anxiety were the most in this study as many as 25 samples $(62.5 \%)$. In this study, there is a tendency relationship between the degree of anxiety by the number of sweat glands secretion. Norepinephrine associated with severity of palmar hyperhidrosis. The highest level of norepinephrine is in the mild grade of palmar hyperhidrosis. There is a tendency correlation between the score of the Hamilton Rating Scale for Anxiety with blood plasma norepinephrine levels.
\end{abstract}

Keywords: Palmar Hyperhidrosis, Anxiety, the Number of Sweat Glands Secretion

\section{Introduction}

Hyperhidrosis (excessive sweating) is about the problem of the skin and that is not common for us, but it happens frequently. Almost $3 \%$ of the world's population suffer from hyperhidrosis. Hyperhidrosis can occur in localized and generalized. [1] In some literature, hyperhidrosis is caused by anxiety which can also be referred to hiperhidrotik [2] and are generally found on the palmar region that is known as palmar hyperhidrosis (PH). Pathophysiology is actually unknown. [3] There are criteria for the diagnosis and severity 
of PH. [4] Objective measurement of the amount of sweat secretion can be measured by gravimetry, which is known as the simple, cheap and fast method. [5]

The Anxiety is an excessive concern at an event or activity that is assessed by the individual as being burdensome or beyond its ability to control it. [6] Stressors are all conditions that perceives danger stimulation and produces stress response. Not all people who experience stressors will suffer from anxiety. Coping skills mechanism play an important role. [7] To determine the scale of anxiety, we can used a measuring tool that is known as the Hamilton Rating Scale for Anxiety (HRS-A). [8] Neurotransmitters that act on the sympathetic nerve stimulation is a norepinephrine (NE), which can trigger an increase in sweat gland. [9]

Psychodermatology is an interaction between mind and skin. Psychiatry focuses on "internal" visible disease and dermatology focuses on "external" visible disease. $\mathrm{PH}$ is a disorder psychophysiology of psychodermatology. [10] Psychophysiology disorder is caused by anxiety. [6] In general, female patients reported who have the highest prevalence in some cases psychodermatology, including $\mathrm{PH}$. [10] People with PH have the bad coping mechanisms ability, resulting in persistent sweat. The cerebral cortex and limbic system also play a important role in $\mathrm{PH}$. PH patients are very sensitive to the hipotalamic sweat centers. The continuously activation of the sympathetic adrenal medullary (SAM) is on $\mathrm{PH}$ [11] (which secrete epinephrine (E) and NE) associated with the excess activity of the sympathetic nervous system. [2] The hypothalamus is activated by anxiety which will result in activation of the sympathetic isolated, it will be causing a reflex response that is highly localized. [12] $\mathrm{PH}$ problem is not fatal but annoying, even can significantly affect quality of life, including professional life, social and psychological. [1] In some references state that research on psychophysiology still very rare. [13] Not many people know that anxiety can trigger hyperhidrosis, especially PH. Throughout the search some references, have not been obtained research on anxiety and neurotransmitters $\mathrm{NE}$ at $\mathrm{PH}$. Because of this problem, the author would like to provide information about the relationship between anxiety and $\mathrm{PH}$.

\section{Material and Methods}

\subsection{Study Design and Patient Specimens}

This study uses an observational analytic with cross sectional design to examine the relationship between anxiety with the number of sweat glands secretion in patients with PH. The study was conducted at the Outpatient Clinic of Dermatology and Venereology Department of Dr. Wahidin Sudirohusodo Hospital, Hasanuddin University Hospital and Senior High School in Makassar. The study began in February until April 2016.

The study population were all $\mathrm{PH}$ patients who met the inclusion criteria and willing to participate in this study by signing the informed concent. Sampling was done by correlation study 2 variables. The inclusion criteria consisted of woman PH, 13 - 64 years old, did not suffer from endocrine disorders, neurological disorders, infectious disorders, malignancies, are not being treated, and patients with $\mathrm{PH}$ who signed an informed concent. Exclusion criteria were the results of laboratory tests of blood plasma NE unreadable/ broken.

Requests for permission from the patient to the research sample, as well as the approval of the Biomedical Research Ethics Committee of the Medicine Faculty, University of Hasanuddin, Makassar. Ethical clearance did not give loss on the subject of research, data confidentiality is maintained, and made informed consent before do this study.

\subsection{Measurement of the Amount of Sweat Secretion}

Subjective assessment of hyperhidrosis generally dubious for several parties. An objective assessment of hyperhidrosis can be done with a gravimetric which is a method to quantitatively measure the amount of sweat secretion. [14] This method can be done on the palmar, facial, axillary and abdomino - lumbar region. [2]

Initially the palmar surface dried with kasa. Patient relaxes for 15 minutes at room temperature of about $24-25^{\circ} \mathrm{C}$. A filter paper that had been weighed before can be used administered to patients. Patients were asked to wipe by themselves slowly at the area of palms for 1 minute (the examiner can use the stopwatch). The filter paper then weighed again and measure the difference between before and after the examination procedure. Do this procedure twice and then use the average value. [5] The forearm is placed on the table with their elbow flexion to lighten the burden of upper limb. [15] Gravimetric value is said to be normal if it is less than $20 \mathrm{mg} / \mathrm{min}$. This procedure is generally done to do some research associated with hyperhidrosis, this procedure has rarely been part of daily clinical practice. [16]

\subsection{Measurement of the Anxiety}

A precise definition and measurement of psychiatric symptoms is very important in the clinical and research fields. After the interview has been done and then the existing symptoms obtained in accordance with the criteria for the diagnosis of the anxiety can be established. To determine the extent of a person's degree of anxiety whether mild, moderate or severe, we can use the measuring instrument/ questionnaire known as the HRS-A. This instrument consists of 14 groups of symptoms that each group elaborated again with the symptoms that are more specific. Each group of symptoms by ratings numbers between $0-4$, which means it is $0=$ no symptoms, $1=1$ from the existing symptoms, 2 = half of the existing symptoms, $3=$ more than half the existing and $4=$ all existing symptoms. [17]

Judgment or use of this measure carried out by health workers or people who have been trained to use it through direct interview techniques. Each of the numerical value of the 14 groups of symptoms is totaled and the sum of the results can be seen the degree of anxiety a person. The total 
value of the numbers (score) are $<6=$ no anxiety, $6-14=$ mild anxiety, $15-27=$ moderate anxiety, and $>27=$ severe anxiety.

Keep in mind that a measuring tool HRS-A is not intended to diagnose anxiety disorders. Anxiety disorder diagnosis is made on the clinical examination by a physician (psychiatrist), while to measure the degree of severity of anxiety disorders was used a measuring tool HRS-A. [8]

\subsection{Statistical Analysis}

Data analysis was performed using SPSS version 22. The statistical method used is the calculation of the mean value (mean), standard deviation (SD) and frequency distribution.

For statistical tests were used, Kolmogorov - Smirnov (to assess the normality of numerical data), Spearman (to assess the correlation between the score HRS-A with high levels of $\mathrm{NE}$ and value gravimetric), ANOVA (to compare scores HRS-A and levels of NE based on the severity of $\mathrm{PH}$, if the result of significant test then continued by follow - up (post hoc) to assess the severity of PH is significant that scored HRS-A and NE are different) and Chi Square (to assess the relationship between the degree of anxiety to the severity of $\mathrm{PH})$. The test results statistically significant if $\mathrm{p}<0,05$.

\section{Result}

This study was performed on 40 samples of patients with PH with the largest age distribution that was less than 20 years as many as 26 samples $(65.0 \%), 20-29$ years as much as 8 samples $(20.0 \%)$, and more equal to 30 years as much as 6 samples $(15.0 \%)$. the minimun of 16 years, maximum of 35 years, with a mean age of $21 \pm 5$ years.

Table 1. Sample Characteristics by Age, Symptoms of PH Minimum 6 months, at Least Lasts For 1 week, Distribution Bilateral Symmetrical, Daily Impact, Early Onset <25 years, Family History, and PH at night.

\begin{tabular}{llll}
\hline Variable & & N & \% \\
\hline Age $^{1}$ & $<20$ years & 26 & 65,0 \\
& $20-29$ years & 8 & 20,0 \\
Minimum 6 months & $>=30$ years & 6 & 15,0 \\
& Yes & 40 & 100,0 \\
At least 1 week & No & 0 & 0,0 \\
& Yes & 40 & 100,0 \\
Bilateral symmetrical & No & 0 & 0,0 \\
& Yes & 40 & 100,0 \\
Daily impact & No & 0 & 0,0 \\
Onset $<25$ years & Yes & 13 & 32,5 \\
& No & 27 & 67,5 \\
Family history & Yes & 40 & 100,0 \\
& No & 0 & 0,0 \\
PH at night & Yes & 12 & 30,0 \\
& No & 28 & 70,0 \\
\hline
\end{tabular}

Table 1 describes the frequency distribution characteristics of the sample according to age, symptoms of $\mathrm{PH}$ at least 6 months, lasting at least 1 week, bilaterally symmetrical distribution, daily impact, onset age $<25$ years, family history, and $\mathrm{PH}$ at night. Symptoms of $\mathrm{PH}$ minimum 6 months, there are in the whole sample as many as 40 samples (100.0\%). PH lasting at least 1 week also found in 40 samples $(100.0 \%)$.

Bilateral and symmetrical distribution found in 40 samples (100.0\%). There is a daily impact on PH patients as many as 13 samples $(32.5 \%)$ and does not impact daily as many as 27 samples $(67.5 \%)$. Onset age suffering from $\mathrm{PH}<25$ years of the 40 samples $(100.0 \%)$. Family history of suffering from $\mathrm{PH}$ found in 12 samples $(30.0 \%)$ and who do not have a family history contained in 28 samples $(70.0 \%)$. PH does not occur 40 samples $(100.0 \%)$ at night.

Table 2. Distribution of Work.

\begin{tabular}{lll}
\hline Work & N & \% \\
\hline $\begin{array}{l}\text { Student } \\
\text { (Senior High School, university student) }\end{array}$ & 26 & 65,0 \\
Professional & & \\
(Pharmacist, nurse) & 3 & 7,5 \\
Housewives & 4 & 10,0 \\
Employee & 7 & 17,5 \\
Total & 40 & 100,0 \\
\hline
\end{tabular}

Table 2 describes the distribution of work in the study sample. Students are the most in this study as many as 26 samples $(65.0 \%)$, there are 3 samples $(7.5 \%)$ of professional workers, 4 samples $(10.0 \%)$ of housewives, and 7 samples $(17,5 \%)$ of employees.

Table 3. Distribution of Onset Age.

\begin{tabular}{lll}
\hline Onset Age & $\mathbf{N}$ & $\mathbf{\%}$ \\
\hline Do not remember & 2 & 5,0 \\
$<6$ years & 1 & 2,5 \\
6-12 years & 14 & 35,0 \\
13-18 years & 21 & 52,5 \\
$>=19$ years & 2 & 5,0 \\
Total & 40 & 100,0 \\
\hline
\end{tabular}

Table 3 describes the distribution of age at onset was first to suffer PH. There are two samples $(5.0 \%)$ who do not remember when suffering from $\mathrm{PH}$ for the first time, the age of first onset suffering from $\mathrm{PH}$ in less than 6 years of age by 1 sample $(2.5 \%)$, aged 6 to 12 years as many as 14 samples (35.0\%), ages 13 to 18 years as many as 21 samples (52.2) and age more equal 19 years as much as 2 samples (5.0\%).

Tabel 4. Distribution of degree of severity of $\mathrm{PH}$.

\begin{tabular}{ll|l}
\hline Degree of severity of $\mathbf{P H}$ & $\mathbf{N}$ & $\mathbf{\%}$ \\
\hline Mild & 12 & 30,0 \\
Moderate & 12 & 30,0 \\
Severe & 16 & 40,0 \\
Total & 40 & 100,0 \\
\hline
\end{tabular}

Table 4 above describes the distribution of the severity of $\mathrm{PH}$ in the sample descriptively. In this study, three degrees of severity of $\mathrm{PH}$, as mild, moderate, and severe. Mild was founded 12 samples (30.0\%). Moderate was founded 12 
samples (30.0\%). Severe was founded 16 samples $(40.0 \%)$.

Tabel 5. Distribution of Degree of Anxiety.

\begin{tabular}{lll}
\hline Degree of anxiety & $\mathbf{N}$ & $\mathbf{\%}$ \\
\hline Unanxiety & 0 & 0,0 \\
Mild & 4 & 10,0 \\
Moderate & 25 & 62,5 \\
Severe & 11 & 27,5 \\
Total & 40 & 100,0 \\
\hline
\end{tabular}

Table 5 above describes the distribution of the degree of anxiety in the sample descriptively. In this study, four degrees of anxiety, unanxiety as much as $0.0 \%$, the degree of anxiety is mild, moderate, and severe. Mild found in 4 samples $(10.0 \%)$. There are the most moderate in this study as many as 25 samples $(62.5 \%)$. Severe was found in 11 samples $(27.5 \%)$.

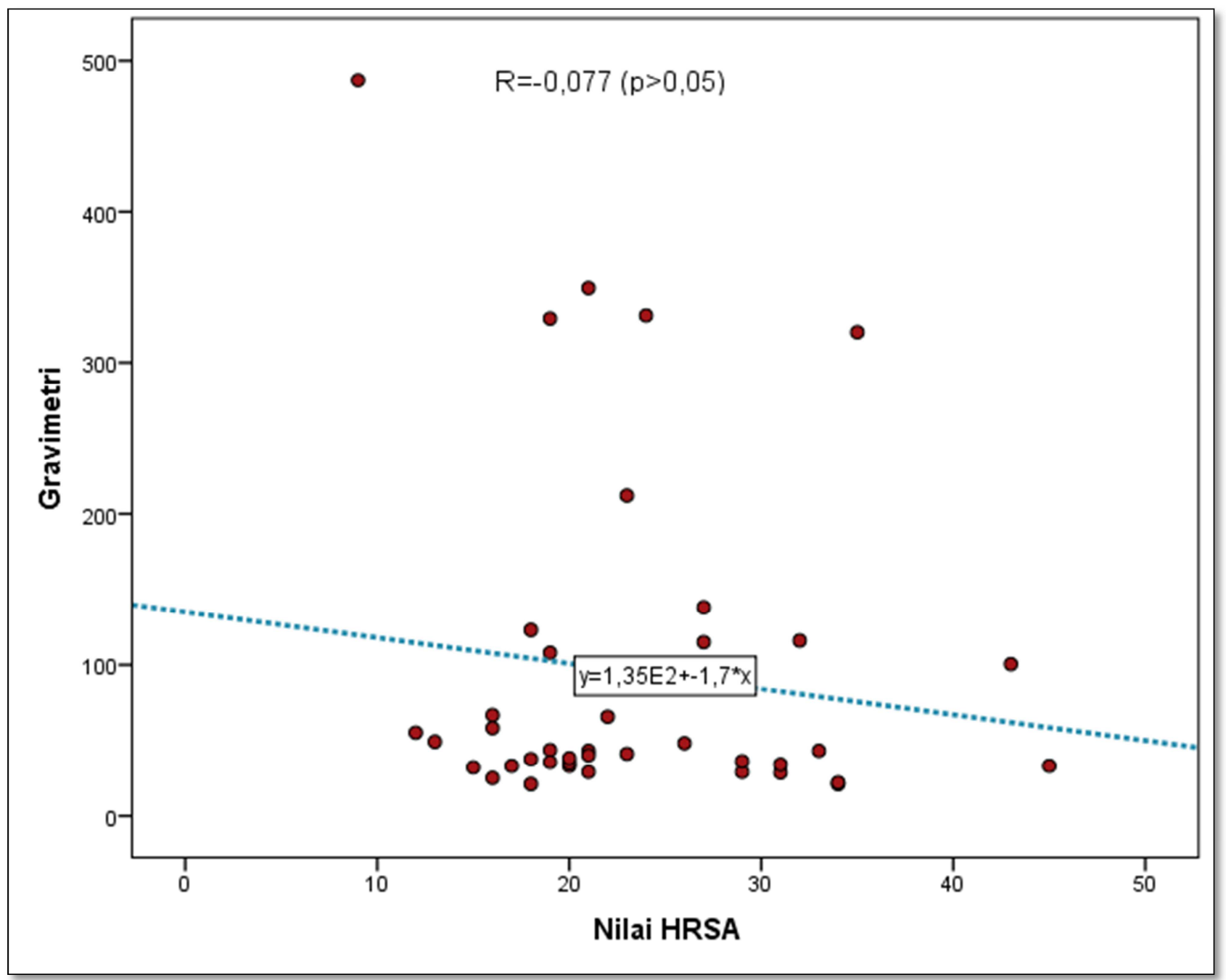

Figure 1. Correlations between scores HRS-A and gravimetric.

In this study, the tendency gravitmetri value decreasing with increasing score HRS-A, although not statistically significant $(p>0.05)$. Correlations between scores HRS-A with gravimetric values can be seen in Figure 1.

Table 6. Ratio between $N E$ and severity of $P H$.

\begin{tabular}{lllll}
\hline Severity of PH & N & Mean & SD & \multicolumn{1}{c}{ P } \\
\hline Mild & 12 & 510,4 & 213,9 & $0,010^{*}$ \\
Moderate & 12 & 306,3 & 86,2 & 143,6 \\
Severe & 16 & 388,9 & & \\
\hline
\end{tabular}

*Anova

Table 6 in this study, there is a difference singnificant NE levels according to the severity of PH ( $\mathrm{p}<0.05)$, where the highest levels of NE significantly on the degree of mild PH (510.4) and lowest in moderate PH degrees (306.3). 


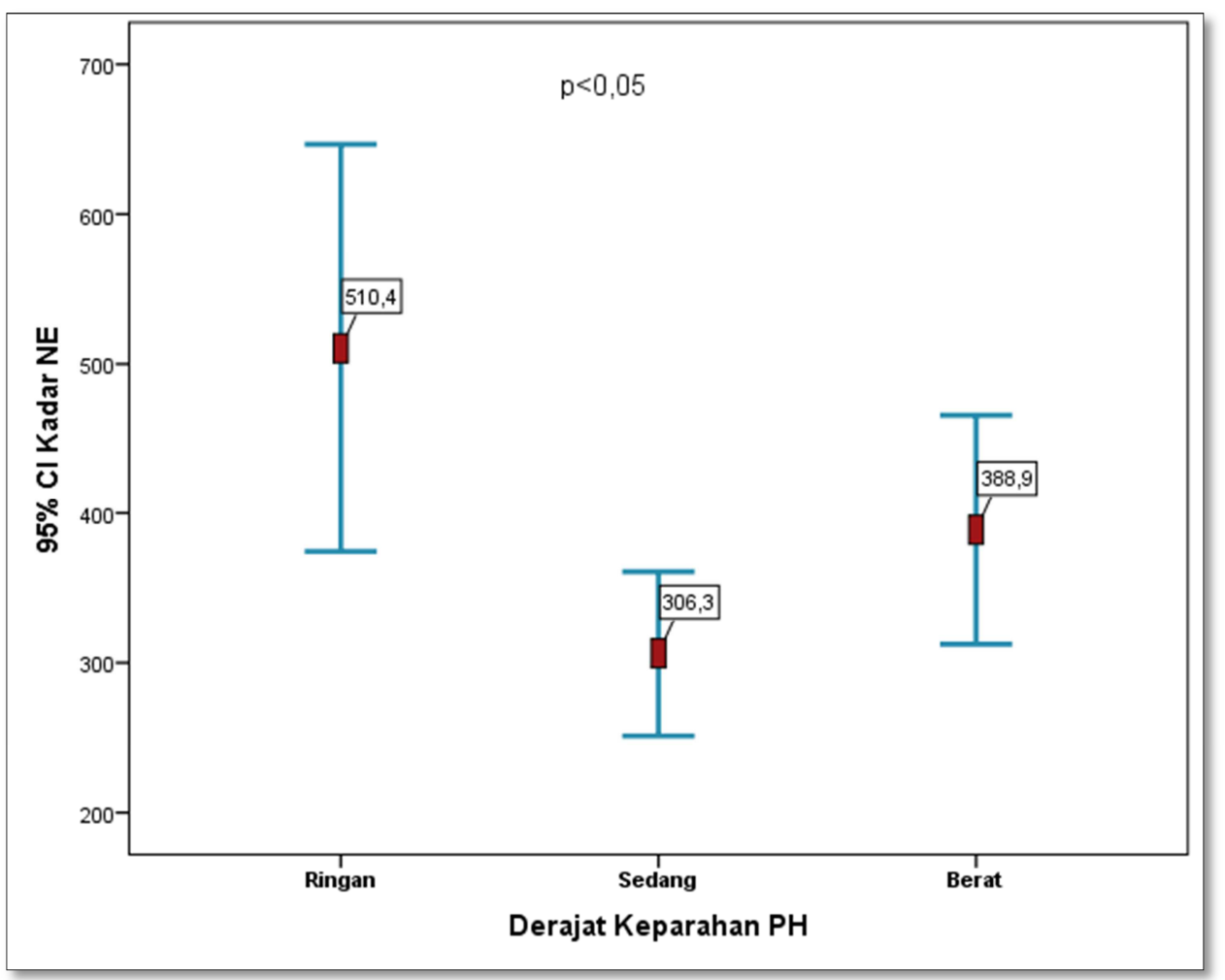

Figure 2. Ratio between $N E$ and severity of $P H$.

The results of further tests carried out on tables 6 and showed that the levels of NE in the mild degree was significantly higher than moderate and severe $(\mathrm{p}<0.05)$. While the moderate to severe did not have difference significantly $(\mathrm{p}>0.05)$. These results were also shown in Figure 2.

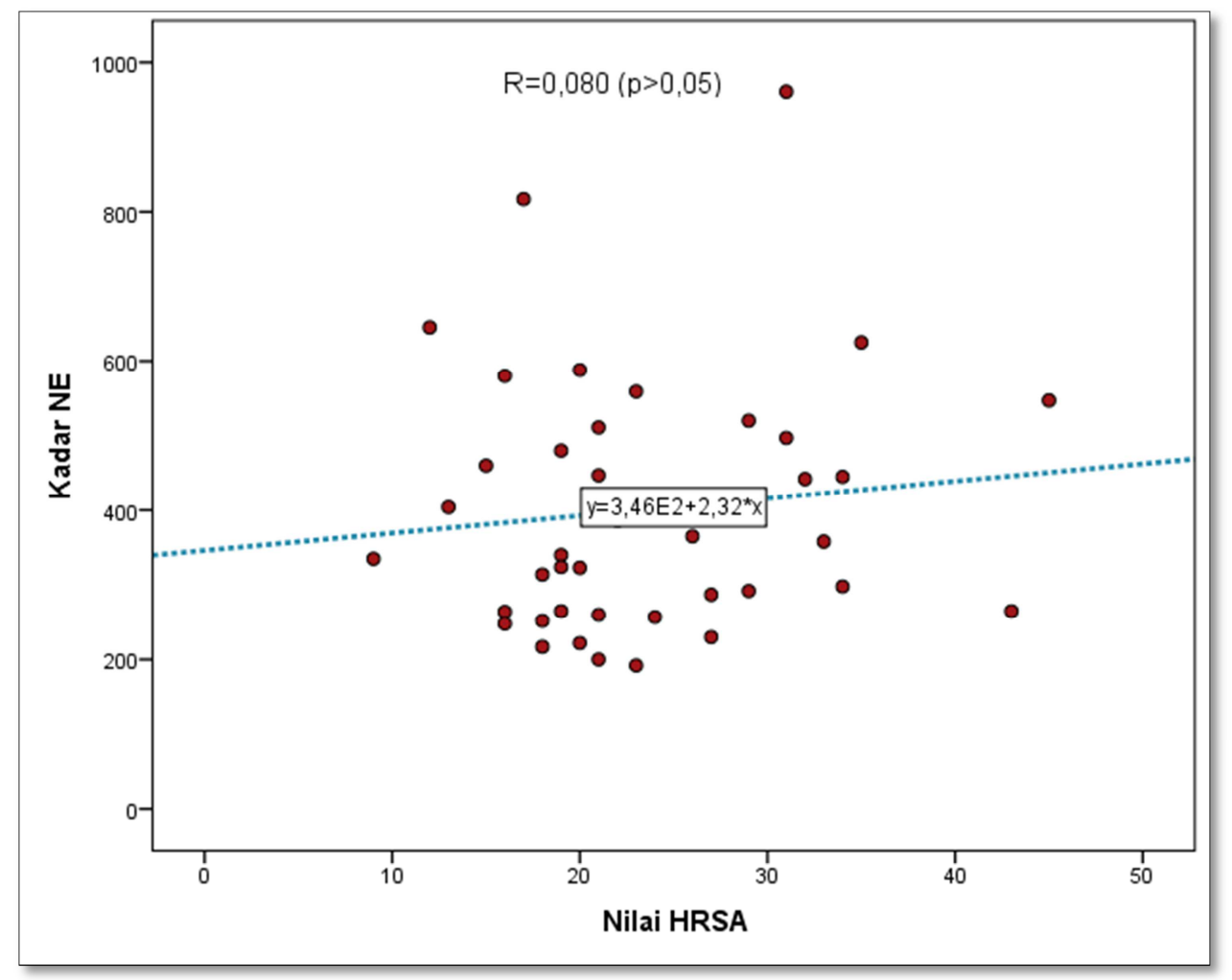

Figure 3. Correlation Scores HRS-A with NE. 
In this study there was no significant relationship between the scores HRS-A and NE levels ( $p>0.05$ ), but NE levels increasing with increasing of the scores HRS-A. Correlations between scores HRS-A with NE levels can be seen in Figure 3.

\section{Discussion}

According to research conducted in Brazil, patients suffering from $\mathrm{PH}$, there are many in the younger population, the second and third decade in life. With a mean age of 23.2 \pm 6.5 years. [18] This is according to Table 1 of this study, where $\mathrm{PH}$ abundant in young population with a mean age of $21 \pm 5$ years.

Student is the kind of work most involved in this study, shown in Table 2 that as many as 26 samples $(65.0 \%)$ of the 40 samples. This is consistent with studies conducted in Korea where students are involved almost half of the study sample, $51.8 \%$. [1]

The criteria for diagnosing $\mathrm{PH}$ is excessive sweating for at least 6 months without being accompanied by abnormalities secondary to two or more of the following symptoms, namely the distribution of bilateral symmetry, lasting at least one week, have an impact on daily activities, onset occurs at age 25 or younger, a positive family history and no sweat at night. [19] In this sample meets these criteria. Generally, these samples do not suffer from a secondary disorder, experiencing excessive sweating for at least 6 months, lasting at least one week, with bilateral symmetrical distribution, the onset of which occurs at age 25 or younger and no sweat at night.

In general, there is a genetic factor in patients with $\mathrm{PH}$, the genes responsible in this case is a gene on chromosome 14q11.2-q13. However, family history of suffering from the same thing in some cases can reach $30.0 \%-50.0 \%$. [20] In this study, a family history of suffering from $\mathrm{PH}$ that is as much as $30.0 \%$, ie 12 samples from 40 samples.

The impact of PH are generally affect the quality of life, even they sometimes refuse to shake hands, grasp stationery, playing musical instruments and other normal activities. Paper that is held to be damaged by damp and held metal will rust. It is burdened themselves thus avoiding some of the daily activities. [20] But in this study, samples having an impact on their daily activities as a result of $\mathrm{PH}$ only around $32.5 \%$, ie 13 samples from 40 samples. In general, they assume that it is a common thing. Interestingly, the average average than they actually feel uncomfortable when looking at her hands dry and not humid sweaty, even they tend to wet hands to wash your hands before performing daily activities.

In the literature of different explains that some patients with $\mathrm{PH}$ also have the potential to have a daily activity that is normal, some of them can change his habits so that they can work on daily activities well, for example by using tissue paper to avoid dilution of ink hair when undergoing writing activities, or they can always bring cloth napkins all the time. [21] Research conducted in Los Angeles explained that only about $20.0 \%$ of the samples were annoyed with the daily activities they experienced PH. [13] But other than that one of the weaknesses of this study is that the study is observational analytic with cross sectional design (crosssectional), which generally do not represent the real situation of the effect of daily impact as a result of the influence of $\mathrm{PH}$

Table 3 on this study describes the distribution of age at onset was first to suffer PH. The greatest number are found in 21 samples $(52.2 \%)$, where the onset of age for the first time at the age of 13 to 18 years. According to the research conducted in Korea in 2010, the mean age of first onset suffering from $\mathrm{PH}$ samples was $15 \pm 8.87$ years. [1] The mean age of onset in this study could not be assessed because there were 2 samples $(5.0 \%)$ that did not remember when they got $\mathrm{PH}$ for the first time, but the numbers mean age of onset was estimated at around the age of $13-18$ years,

Primary hyperhidrosis is an idiopathic disease, which in most cases, no underlying disease, but according to some references commonly associated with anxiety. [15] The study conducted in Spain describes the relationship between primary hyperhidrosis with anxiety, most of the samples in this study suffered from PH around 93.6\%. [3] The degree of anxiety consisted of unanxiety, mild, moderate, and severe. HRS-A is the grading scale was developed to measure the severity of anxiety. Quantitative assessment of the most commonly performed to measure the amount of sweat gland secretion is using a gravimetric. [19]

In the study can be seen in Figure 2, there is not a significant correlation between the scores HRS-A with a gravimetric value, but there is a tendency where gravitmetri value decreases with increasing score HRS-A. Research conducted in Poland comparing the gravimetric values in healthy individuals with hyperhidrosis sufferers. The results of these studies showed that palmar gravimetric values in normal individuals and patients with $\mathrm{PH}$ respectively are \pm $18.49 \mathrm{mg} / \mathrm{min}$ and $\pm 46 \mathrm{mg} / \mathrm{min}$. [5] An objective assessment of a gravimetric considered normal if it is less than $20 \mathrm{mg} / \mathrm{min}$. [22] Many of references that compares gravimetric values before and after treatment modality, but have not found any reference that compares the number of sweat glands secretion to the degree of anxiety.

The severity of the PH can be assessed subjectively. Some researchers said it was important to assess the severity of $\mathrm{PH}$, especially to determine the progress of therapy. Neurotransmitters that act on the sympathetic nerve stimulation is NE which can trigger an increase in sweat gland [4], in addition to the NE can be affected by factors of anxiety. [23] NE levels can be extracted from the blood plasma through laboratory tests by ELISA.

Initially the stress response in the form of anxiety can increase the activity of SAM, fight or flight response. Increased sympathetic activity will stimulate the adrenal glands and the medulla part serelus locus in the brain stem, causing the release of catecholamines, for example NE in the circulating blood. When the fight or flight response can be resolved, then the individual will experience a relaxation response. But if the acute response that fails to be resolved, 
then the body will make the general adaptation mechanism and will switch to the chronic stress response. Glukortikoid especially cortisol is the important role in this response. Cortisol has a direct negative feedback effect on the formation of corticotropin releasing hormone (CRF) and adrenocortocotropic hormone (ACTH). Both of these feedback helps to regulate cortisol concentrations in blood plasma, and it can decrease cortisol in the plasma when the person is not anxiety. However, if there are continuously and in the long term stimuli stressors, then it can result in the feedback path inhibitor directly from cortisol becomes inadequate, thus causing exacerbation periodic secretion of cortisol at various times or prolongation of cortisol secretion. [12]

In the study shown in Table 6, the highest levels of NE were found in the severe than moderate and severe of $\mathrm{PH}$. Most of the samples in this study suffered from $\mathrm{PH}$ to the severity of the severe, but the levels of NE as acute stress hormones were found lower in this study. Therefore, the onset of the first time the sample suffered from $\mathrm{PH}$ plays an important role, which in this study based on the history of the onset of the first time the sample suffered from $\mathrm{PH}$, obtained mostly from patients with severe $\mathrm{PH}$, onset of their first time suffering from $\mathrm{PH}$ is between aged less than 6 years and $6-$ 12 years, when sample was still in grade kindergarden through elementary school. The history is based on autoanamnesis and alloanamnesis. Therefore there is the possibility of suffering from chronic stress response, so the NE hormone did not contribute much. Chronic stress response is the stressors that take in the period long time. [24] Duration of chronic stress response according to some references dependent on a few individuals, but generally occurs in months to years.

Research on the effect of NE levels and severity of PH are still not found, but there has been studies done in Germany, which discusses the relationship between primary hyperhidrosis with chronic stress level as co etiologic factors of depression. However, this study is not limited to $\mathrm{PH}$, but discuss overall of primary hyperhidrosis. According to the study mentioned that there is a relationship between chronic stress response to cortisol. Individuals with primary hyperhidrosis suffer more chronic stress response and more symptoms of depression than the general population. The stress response is divided into acute, episodic or chronic stress responce. Some of the factors associated with these stressors to the duration of the condition. In this reference just mentioned that the individual will experience chronic stress response in a considerable period of time and measure it by Trier Inventory of Chronic Stress ('Trierer inventar zum chronischen Stress': TICs). [2]

In Figure 3, there are no significant correlation between the scores HRS-A and NE levels ( $p>0.05)$, but it looks to be a trend NE levels increasing with increasing score HRS-A. Research on the comparison between the scores HRS-A grading NE blood plasma, still can not be found, it has just been reported the realiabilitas and validiti of HRS-A to assess the degree of anxiety which is still acceptable and still widely used both in clinical and in the field of research. There is research conducted by Ramos et al, about the relationship between primary hyperhidrosis with anxiety, but the scale used of State Trait Anxiety Inventory (STAI) and Anxiety Specific Questionnaire for Primary Hyperhidrosis (ASQPH), but, this research is not limited to $\mathrm{PH}$ only. According to this study, STAI can not be portrait anxiety levels well, and the ASQPH portrait primary hyperhidrosis not $\mathrm{PH}$. [3]

\section{Conclusion}

In this study, there is a tendency relationship between the degree of anxiety by the number of sweat glands secretion. Levels of NE related to the severity of $\mathrm{PH}$, where the highest levels of NE in mild PH. There is a tendency relationship between the score HRS-A with a blood plasma NE levels. Based on this study, need to do research with cohort study design with a larger sample size.

\section{References}

[1] Park, E. J., et al., An Epidemiological Study of Hyperhidrosis Patients Visiting the Ajou University Hospital Hyperhidrosis Center in Korea. J Korean Med Sci, 2010. 25: p. 772-775.

[2] Gross, K. M., et al., Elevated Social Stress Levels and Depressive Symptoms in Primary Hyperhidrosis. Plos One, 2014. 9 (3): p. 1-6.

[3] Ramos, R., et al., Primary Hyperhidrosis and Anxiety: a Prospective Preoperative Survey of 158 Patients. Arch Bronconeumol, 2005. 41 (2): p. 88-92.

[4] Lakraj, A.-A. D., N. Moghimi, and B. Jabbari, Hyperhidrosis: Anatomy, Pathophysiology and Treatment with Emphasis on the Role of Botulinum Toxins. Toxins, 2013. 5: p. 821-840.

[5] Stefaniak, T. J. and M. Proczko, Gravimetry in sweating assessment in primary hyperhidrosis and healthy individuals. Clin Auton Res, 2013. 23: p. 197-200.

[6] Leon, A., E. C. Levin, and J. Y. M. Koo, Psychodermatology: An Overview. Semin Cutan Med Surg, 2013. 32: p. 64-67.

[7] Rasmun, Stres, in Stres, Koping dan Adaptasi 2004, Sagung Seto: Jakarta. p. 7-22.

[8] Hawari, D., Kecemasan, in Manajemen Stres, Cemas dan Depresi 2013, Fakultas Kedokteran Universitas Indonesia: Jakarta. p. 63-83.

[9] Sherwood, L., Sistem Saraf Perifer: Divisi Eferen, in Human Physiology: From Cells to System 2001, A division of International Thomsom Publishing. p. 196-211.

[10] Jafferany, M., Psychodermatology: A Guide to Understanding Common Psychocutaneous Disorders. J Clin Psychiatry, 2007. 9: p. 203-213.

[11] Cohen, S., D. Janicki-Deverts, and G. E. Miller, Psychological Stress and Disease. JAMA, 2007. 298 (14): p. 1685-1687.

[12] Guyton, A. C. and J. E. Hall, Otonom Medula Adrenal, in Textbook of Medical Physiology, D. Widjajakusumah and A. Tanzil, Editors. 2013, W. B. Saunders Company: Philadelpihia. p. 957-973. 
[13] Wheaton, M. G., A. E. Braddock, and J. S. Abramowitz, The Sweating Cognitions Inventory: A Measure of Cognitions in Hyperhidrosis. J Psychopathol Behav Assess, 2011. 33: p. 393-402.

[14] Schlereth, T., M. Dieterich, and F. Birklein, Hyperhidrosis Causes and Treatment of Enhanced Sweating. Dtsch Arztebl Int, 2009. 106 (3): p. 32-37.

[15] Kalantaria, K. K., et al., The Effect and Persistency of $1 \%$ Aluminum Chloride Hexahydrate Iontophoresis in the Treatment of Primary Palmar Hyperhidrosis. IJPR, 2011. 10 (3): p. 641-645.

[16] Khalid, S. G., Quantification of Hyperhidrosis using Electronic Sudometer, in Quantification of Hyperhidrosis using Electronic Sudometer, B. J. Sjöberg, Editor 2013, Royal Institute of Technology: Sweden. p. 1-43.

[17] Hamilton, M., The assessment of anxiety states by rating. Br J Med Psychol, 1959. 32: p. 50-55.

[18] Yazbek, G., et al., Twenty Months of Evolution Following Sympathectomy on Patients with Palmar Hyperhidrosis: Sympathectomy at the T3 Level is Better Than at the T2 Level. Clinics, 2009. 64 (8): p. 743-749.
[19] Walling, H. W. and B. L. Swick, Treatment Options for Hyperhidrosis. Am J CIln Dermotol, 2011. 12 (5): p. 266-295.

[20] Leung, A. K. and B. Barankin, Palmar Hyperhidrosis. J Neonatol Clin Pediatr, 2014. 1 (1): p. 1-2.

[21] Berntsen, B. and R. Gupta, Daily oscillations of sweating in hyperhidrotic individuals before and after treatment with botulinum toxin A. CMAJ, 2006: p. 1-33.

[22] Haider, A. and N. Solish, Focal hyperhidrosis: diagnosis and management. CMAJ, 2005. 172 (1): p. 1-7.

[23] Goddard, A. W., et al., Current Perspectives of The Roles of The Central Norephrine Suystem in Anxiety and Depression. Depress Anxiety, 2010. 27: p. 339-350.

[24] Akbar, T. M., et al., Efficacy and safety of tap water iontophoresis for palmoplantar hyperhidrosis. JPAD, 2013. 23 (3): p. 304-309. 